\title{
Yttrium-90 distribution following radiosynoviorthesis of the knee joint in rheumatoid arthritis patients: a SPECT/CT study
}

\author{
A. Bielińska • M. Korkosz • J. Gąsowski • M. Tomaszuk • \\ A. Staszczak-Sowa • B. Kwaśny-Krochin • M. Buziak-Bereza • \\ A. Hubalewska-Dydejczyk • T. Grodzicki
}

Received: 7 October 2013/Accepted: 19 February 2014/Published online: 5 March 2014

(C) The Author(s) 2014. This article is published with open access at Springerlink.com

\begin{abstract}
Objective To examine yttrium-90 distribution 1 and $72 \mathrm{~h}$ following its injection into a knee joint in patients with rheumatoid arthritis (RA).

Methods In 14 RA patients we injected yttrium-90 into the affected knee joint using lateral approach. To assess the radioisotope distribution in the joint, the superimposed sequential SPECT and CT imaging was performed 1 and $72 \mathrm{~h}$ after the injection. We analyzed the percentage of radioisotope distribution in three predefined compartments of the knee joint (lower, upper medial, upper lateral).

Results After 1 and $72 \mathrm{~h}$, the mean percentage distributions were, respectively, 7.14 and $23.07 \%$ in lower; 21.42 and $15.38 \%$ in upper medial, and 71.42 and $61.53 \%$ in upper lateral compartment. The percentage of isotope
\end{abstract}

A. Bielińska $(\bowtie) \cdot$ B. Kwaśny-Krochin

Department of Rheumatology and Balneology, Jagiellonian

University Medical College, Sniadeckich 10, 31-501 Kraków,

Poland

e-mail: aneta.bielinska@uj.edu.pl

\section{Korkosz}

Division of Rheumatology, Department of Internal Medicine and Gerontology, Jagiellonian University Medical College, Kraków, Poland

J. Gąsowski · T. Grodzicki

Department of Internal Medicine and Gerontology, Jagiellonian University Medical College, Kraków, Poland

M. Tomaszuk

Nuclear Medicine Unit, Department of Endocrinology,

University Hospital in Krakow, Kraków, Poland

A. Staszczak-Sowa · M. Buziak-Bereza •

A. Hubalewska-Dydejczyk

Nuclear Medicine Unit, Department of Endocrinology,

Jagiellonian University Medical College, Kraków, Poland deposition did not change significantly with time in any of the compartments (all $p>0.26$ ). The deposition of isotope, both at 1 and $72 \mathrm{~h}$, was significantly greater in upper lateral compartment, where the injection was performed, than in all other compartments (all $p<0.05$ ).

Conclusions Using the SPECT/CT hybrid method, we proved that the majority of isotope is located at the compartment adjacent to the injection. Two injections targeting different compartments might improve the clinical efficacy of the procedure.

Keywords Rheumatoid arthritis - Radiosynoviorthesis · Yttrium-90 isotope $\cdot$ SPECT/CT

\section{Introduction}

Radiosynoviorthesis (RSO) is a safe and effective therapeutic modality for synovitis in inflammatory arthritis [13]. It was developed as an alternative to or preceding the surgical synovectomy [4]. The main indication is a chronic synovitis of affected knee in rheumatoid arthritis (RA). Yttrium-90 $\left({ }^{90} \mathrm{Y}\right)$, a radionuclide with an intense $\beta$-emission, is most widely used for the treatment of knee joint. Efficacy of the RSO is estimated at 60-80\% [3]. However, the accurate prediction of the efficacy of RSO is difficult due to patient-related factors such as the type, course, and inflammatory activity within the joint $[2,5]$. On average, penetration of radiation following RSO approximates $10 \mathrm{~mm}[6,7]$. Therefore, the efficacy of RSO largely depends on the radionuclide distribution within the joint.

Single photon emission computed tomography (SPECT/ $\mathrm{CT}$ ) is a novel hybrid imaging method that combines functional data from SPECT and anatomic data from CT, sequentially acquired during single examination [8]. SPECT 
creates computer-generated images of radionuclide distribution, while CT enables 3D anatomical images of joint.

The majority of published studies assessed the distribution of radionuclide using gamma camera/SPECT imaging yielding imprecise information which does not reflect the uptake of radionuclide into the anatomic compartments of the knee. Nevertheless, the gamma camera imaging provided an evidence that even high degree of standardization of the procedure, including site of injection, needle gouge does not prevent unpredictable distribution patterns [9]. Moreover, there are no guidelines for follow-up time needed to assess RSO efficacy.

The aim of this study was to assess, using SPECT/CT, the yttrium-90 radionuclide distribution 1 and $72 \mathrm{~h}$ following its injection into RA affected knee joint.

\section{Methods}

We prospectively enrolled 14 consecutive patients diagnosed with RA according to 1987 American College of Rheumatology criteria [10]. Knee synovitis had to be present despite treatment with disease-modifying antirheumatic drugs and at least one intra-articular administration of long acting steroid. We excluded patients with ruptured popliteal cyst, pregnant or breast-feeding or unable to give informed consent.

\section{Procedures}

\section{Radiosynoviorthesis}

Radiosynoviortheses with beta emitting radionuclide injected into the knee joint were performed according to European Association of Nuclear Medicine guidelines [3]. The yttrium-90 $\left({ }^{90} \mathrm{Y}\right)$, Colloid CIS bio international colloid suspension for local injection (IBA Molecular, France), with mean activity of $220 \mathrm{MBq}$, was administered into each predetermined knee. Arthrocentesis of the knee with $1.2 \mathrm{~mm}$-gauge needle was carried out from lateral approach by experienced rheumatologist. One needle was used for all intraarticular procedures. Effusion, if present, was aspirated before radionuclide injection which was immediately followed by intraarticular administration of $7 \mathrm{mg}$ of betamethasone. After steroid injection the knee was passively bent several times and splinted for $48 \mathrm{~h}$.

\section{SPECT/CT assessment}

In order to assess the radioisotope distribution in the joint space and to find the possible leakage of radioisotope outside the joint, the SPECT/CT examinations were performed. A hybrid system Symbia TruePoint T16 camera (Siemens) with parallel, medium energy collimators was used. The yttrium-90 $\left({ }^{90} \mathrm{Y}\right)$ tracer was injected in each target knee. All patients underwent SPECT/CT examination of the knee 1 and $72 \mathrm{~h}$ after the injection of the radionuclide. Settings of SPECT scan were as follows: $180^{\circ}$ orbit for each head, step and shoot mode, 40 images, at $32 \mathrm{~s}$ per view, $128 \times 128$ matrix. The acquired data were reconstructed using the ordered subset expectation maximization (OSEM) FLASH 3D iterative reconstruction method with eight subsets and ten iterations. Setting of CT part of the study was as follows: $130 \mathrm{kV}$, effective $\mathrm{mA} \mathrm{s}$ 190 with CAREDose4D system, slice thickness $5.0 \mathrm{~mm}$, acq. $16 \times 1.2 \mathrm{~mm}$ and reconstruction increment $3.0 \mathrm{~mm}$ with B50s moderate kernel shaped. Each SPECT/CT was evaluated on an ongoing basis by the medical physicist. In case of suspicion of leakage of the isotope beyond the joint, assessment was extended to regional lymph nodes.

Knee joint was divided into three ellipsoid 3D shaped regions of interest (ROI) according to the predefined anatomical compartments: upper lateral, upper medial and lower (Fig. 1a). Percentage analysis of radioisotope distribution in three compartments was performed during SPECT/CT examinations (each in $72 \mathrm{~h}$ apart). The total amount of injected yttrium-90 $\left({ }^{90} \mathrm{Y}\right)$ was considered as $100 \%$. The number of counts in each ROI was evaluated using manufacturer provided volumetric analysis. The percentage of uptake [\%] in each region was assessed according to the formula: [\%] = number of counts in the region/the sum of counts from all regions $\times 100$.

The study was approved by the local bioethics committee, and written informed consent was obtained prior to the enrollment.

\section{Statistical analysis}

Data were analysed using SAS 9.2 software (SAS Institute Inc. Cary, NC, USA). First we established the normality of frequency distributions. Then, we used the Student's $t$ test and univariate ANOVA model to check for the betweencompartment, and within-compartment time-related differences, respectively.

\section{Results}

Mean \pm SD age of patients was $53 \pm 12$ years, with mean RA duration prior to the study of $5.46 \pm 3.31$ years. The mean percentage distributions of the isotope within compartments, after 1 and $72 \mathrm{~h}$, respectively, were as follows: in the lower compartment 7.14 and $23.07 \%$; in the upper medial compartment 21.42 and $15.38 \%$; in the upper lateral compartment 71.42 and $61.53 \%$. After $1 \mathrm{~h}$ of injection, we 
A

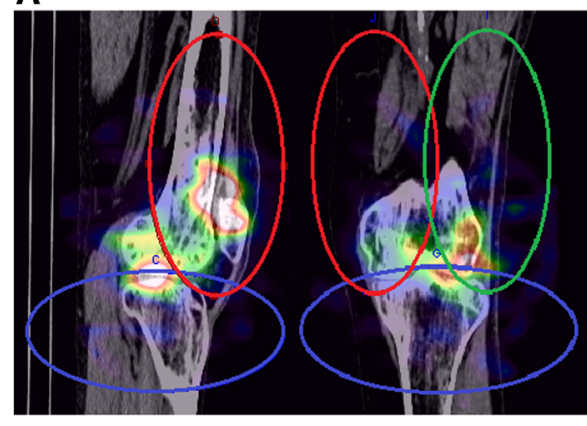

B

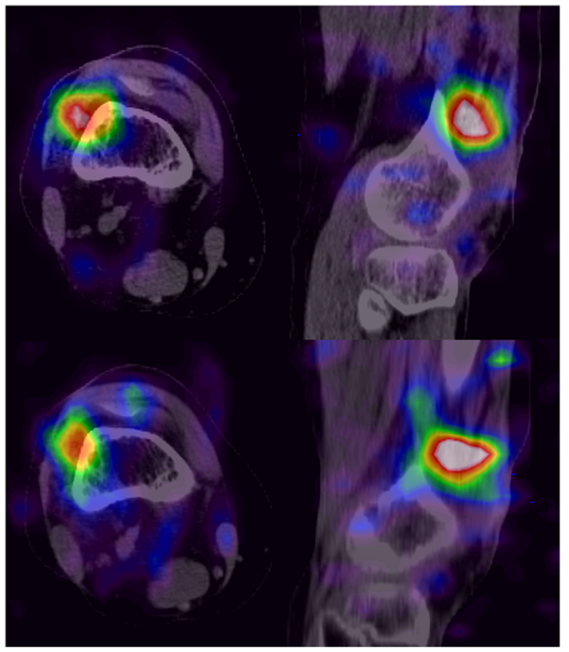

Fig. 1 Radioisotope distribution within the knee joint. a Ellipsoid 3D predefined regions of interest: upper lateral (green), upper medial (red) and lower (blue) compartments for isotope distribution measurement. b The example of the average distribution of yttrium90 in the knee joint 1 and $72 \mathrm{~h}$ after procedure (color figure online)

Table 1 The radioisotope colloid distribution into the knee joint space examined by SPECT/CT method

\begin{tabular}{|c|c|c|c|c|c|c|c|c|c|c|c|c|}
\hline \multirow{3}{*}{$\begin{array}{l}\text { Patient } \\
\text { no. }\end{array}$} & \multicolumn{4}{|c|}{ Lower compartment } & \multicolumn{4}{|c|}{ Upper medial compartment } & \multicolumn{4}{|c|}{ Upper lateral compartment } \\
\hline & \multicolumn{2}{|c|}{ T0 (after $1 \mathrm{~h}$ ) } & \multicolumn{2}{|c|}{ T1 (after $72 \mathrm{~h}$ ) } & \multicolumn{2}{|c|}{ T0 (after $1 \mathrm{~h}$ ) } & \multicolumn{2}{|c|}{ T1 (after 72 h) } & \multicolumn{2}{|c|}{ T0 (after $1 \mathrm{~h})$} & \multicolumn{2}{|c|}{ T1 (after 72 h) } \\
\hline & $\begin{array}{l}\text { Measured } \\
\text { value }\end{array}$ & $\begin{array}{l}\text { Ratio } \\
(\%)\end{array}$ & $\begin{array}{l}\text { Measured } \\
\text { value }\end{array}$ & $\begin{array}{l}\text { Ratio } \\
(\%)\end{array}$ & $\begin{array}{l}\text { Measured } \\
\text { value }\end{array}$ & $\begin{array}{l}\text { Ratio } \\
(\%)\end{array}$ & $\begin{array}{l}\text { Measured } \\
\text { value }\end{array}$ & $\begin{array}{l}\text { Ratio } \\
(\%)\end{array}$ & $\begin{array}{l}\text { Measured } \\
\text { value }\end{array}$ & $\begin{array}{l}\text { Ratio } \\
(\%)\end{array}$ & $\begin{array}{l}\text { Measured } \\
\text { value }\end{array}$ & $\begin{array}{l}\text { Ratio } \\
(\%)\end{array}$ \\
\hline 1 & $187,082.0$ & 17.3 & $160,291.3$ & 34.0 & $484,612.4$ & 44.9 & $166,620.9$ & 35.4 & $40,858.3$ & 37.8 & $144,356.6$ & 30.6 \\
\hline 2 & $217,307.1$ & 21.0 & $127,637.3$ & 28.5 & $335,644.8$ & 32.5 & $194,931.8$ & 43.6 & $480,038.4$ & 46.5 & $124,793.7$ & 27.9 \\
\hline 3 & $245,048.1$ & 27.2 & $144,419.4$ & 38.2 & $343,020.1$ & 38.0 & $112,091.4$ & 29.6 & $313,543.0$ & 34.8 & $121,849.3$ & 32.2 \\
\hline 4 & $64,939.4$ & 7.5 & $20,950.9$ & 13.7 & $186,765.1$ & 21.6 & $26,292.3$ & 17.2 & $613,708.4$ & 70.9 & $105,246.2$ & 69.0 \\
\hline 5 & $58,825.2$ & 10.3 & $64,441.6$ & 17.6 & $133,025.3$ & 23.3 & $150,761.8$ & 41.1 & $378,311.1$ & 66.3 & $151,367.9$ & 41.3 \\
\hline 6 & $80,293.5$ & 31.2 & $276,710.3$ & 30.5 & $96,891.2$ & 37.6 & $307,239.7$ & 33.8 & $80,179.1$ & 31.1 & $324,050.1$ & 35.7 \\
\hline 7 & $73,337.4$ & 28.2 & $69,108.2$ & 10.1 & $71,726.6$ & 27.5 & $279,255.6$ & 40.7 & $115,310.6$ & 44.3 & $337,686.4$ & 49.2 \\
\hline 8 & $28,775.6$ & 7.8 & $21,597.8$ & 9.2 & $39,720.1$ & 10.7 & $31,132.0$ & 13.2 & $302,540.8$ & 81.5 & $182,240.8$ & 77.6 \\
\hline 9 & $114,714.3$ & 8.0 & & & $361,218.5$ & 26.0 & & & $905,109.1$ & 66.0 & & \\
\hline 10 & $72,946.2$ & 9.3 & $78,084.6$ & 11.4 & $133,805.9$ & 17.1 & $141,477.4$ & 20.7 & $575,082.2$ & 73.6 & $464,146.0$ & 67.9 \\
\hline 11 & $93,577.8$ & 37.5 & $44,320.3$ & 42.7 & $75,823.4$ & 30.4 & $33,047.0$ & 31.8 & $79,817.9$ & 32.0 & $26,398.4$ & 25.4 \\
\hline 12 & $64,144.3$ & 29.6 & $36,393.9$ & 37.0 & $63,848.2$ & 29.5 & $30,732.5$ & 31.2 & $88,605.2$ & 40.9 & $31,319.1$ & 31.8 \\
\hline 13 & $17,597.1$ & 6.6 & $8,672.9$ & 7.5 & $44,348.0$ & 16.5 & $18,703.9$ & 16.7 & $205,999.4$ & 76.9 & $88,372.5$ & 76.3 \\
\hline 14 & $45,041.6$ & 21.9 & $24,868.4$ & 32.2 & $58,956.9$ & 28.7 & $21,640.9$ & 28.0 & $101,222.8$ & 49.3 & $30,667.1$ & 39.7 \\
\hline
\end{tabular}

found significant differences of uptake between compartments, with the greatest percentage of isotope deposition at the upper lateral compartment which was adjacent to the injection site (all $p<0.003$ ), (Table 1). This did not change materially $72 \mathrm{~h}$ post procedure, with significant difference between the compartment of the injection site and each of the remaining two (Fig. 2). The percentage of isotope deposition did not change significantly with time at any of the compartments (all $p>0.26$ ) (Table 1).

\section{Discussion}

We found that the distribution of yttrium-90 $\left({ }^{90} \mathrm{Y}\right)$ isotope following its intra-articular injection into the knee joint in RA patients highly depends on the site of injection. The deposition was greatest in the upper lateral compartment into which the isotope was injected, and this did not change significantly $72 \mathrm{~h}$ after the procedure (Fig. 2). The innovative approach of our study was to use the SPECT/CT 


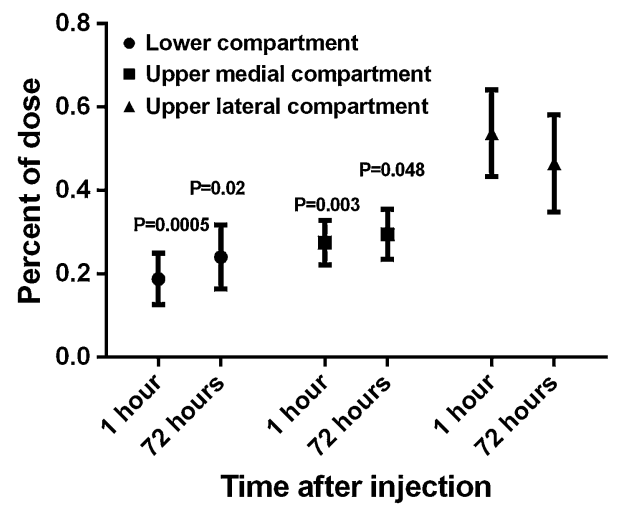

Fig. 2 The distribution of yttrium-90 in three knee compartments 1 and $72 \mathrm{~h}$ after radiosynoviorthesis. $P$ values for comparisons between upper lateral compartment (injection site) and two other compartments, 1 and $72 \mathrm{~h}$ after procedure, respectively. The error bars are $95 \%$ confidence intervals

which enabled accurate anatomical localization of the deposited isotope (Fig. 1b).

To the best of our knowledge, so far only two studies assessed the distribution of an isotope, following the injection into a knee. Jahangier et al. studied 69 patients in whom RSO was performed [9]. They used the gammacamera based detection of the distribution of the isotope, which does not permit the accurate anatomical visualization. They found that in the majority of patients (54\%) the deposition was diffuse. However, only $28 \%$ of their group were RA patients. Furthermore, they did not standardize the time of the assessment, which was performed immediately or $24 \mathrm{~h}$ after injection, making it impossible to study the time-related changes in isotope distribution. Likewise, Jahangier et al. failed to report whether the deposition was related to the site of injection. We used a hybrid method enabling accurate anatomical visualization of the isotope within a knee which enabled us to prove that the isotope is deposited predominantly at the site of injection, which in our study was standardized, and that deposition does not change after $72 \mathrm{~h}$ of follow-up.

Vuorela et al. did a feasibility study on six RA patients [6]. In order to localize synovitis they administered a ${ }^{99 \mathrm{~m}} \mathrm{Tc}$-immunoglobulin $\left[{ }^{99 \mathrm{~m}} \mathrm{Tc}-\mathrm{HIG}\right]$ labeled anti-synovial antibody. Then they treated the patients with 166 Holmium ferric hydroxide macroaggregates $\left({ }^{166} \mathrm{Ho}\right.$-FHMA), and reassessed the SPECT/MRI. The authors concluded that the hybrid method using MRI and SPECT is feasible, and that the administration of an isotope-labeled antibody can help localize synovitis. However, the patient was exposed to two sources of radiation including one injected systemically (500-550 MBq), and one injected intra-articularly $(0.9-1.0 \mathrm{GBq})$, and further used gadolinium-enhanced MRI scanning. We also used the gadolinium-enhanced MRI to localize synovitis, however, we did not use the isotope-labeled anti-synovial antibodies. The SPECT/CT required single source of radiation of $220 \mathrm{MBq}$, and the CT equipment we used featured a low-energy scanner.

Our results must be considered within the context of the study's limitations. Slight overlapping of ellipsoids is visible on presented 2D figure (Fig. 1a) but it mostly covers bone regions or other anatomical structures outside the joint cavity. The overlap is estimated to be less than $10 \%$ but might have certain impact on our results.

In conclusion, our data are the first to show, using the SPECT/CT hybrid method of visualization, the precise anatomical distribution of injected isotope, and the fact that the distribution does not change over the standardized, $72 \mathrm{~h}$ time of imaging follow-up. The fact that the majority of isotope, as opposed to findings by Jahangier et al. is located close to the site of injection, inclines us to hypothesize that two injections at two different sites targeting different knee compartments might improve the distribution of isotope. Alternatively, a larger volume of radioisotope colloid suspension might enhance the distribution of yttrium-90 within the knee joint and augment the clinical outcome of the procedure. However, further studies are needed to assess these hypotheses.

Acknowledgments All authors revised and approved this version of this manuscript and approved the mention of their names in the article. This work was supported by Jagiellonian University Medical College, Krakow, Poland.

Conflict of interest No, there are no competing interests.

Open Access This article is distributed under the terms of the Creative Commons Attribution License which permits any use, distribution, and reproduction in any medium, provided the original author(s) and the source are credited.

\section{References}

1. Kampen WU, Voth M, Pinkert J, Krause A. Therapeutic status of radiosynoviorthesis of the knee with yttrium [90Y] colloid in rheumatoid arthritis and related indications. Rheumatology (Oxford, England). 2007;46(1):16-24.

2. Heuft-Dorenbosch LL, de Vet HC, van der Linden S. Yttrium radiosynoviorthesis in the treatment of knee arthritis in rheumatoid arthritis: a systematic review. Ann Rheum Dis. 2000;59(8):583-6.

3. Clunie G, Fischer M, EANM. EANM procedure guidelines for radiosynovectomy. Eur J Nucl Med Mol Imaging. 2003;30(3):BP12-BP16.

4. Chrapko B, Zwolak R, Nocun A, Golebiewska R, Majdan M. Radiation synovectomy with $90 \mathrm{Y}$ colloid in the therapy of recurrent knee joint effusions in patients with inflammatory joint diseases. Rheumatol Int. 2007;27(8):729-34.

5. Pirich C, Schwameis E, Bernecker P, Radauer M, Friedl M, Lang $\mathrm{S}$, et al. Influence of radiation synovectomy on articular cartilage, synovial thickness and enhancement as evidenced by MRI in patients with chronic synovitis. J Nucl Med Off Publ Soc Nucl Med. 1999;40(8):1277-84. 
6. Vuorela J, Kauppinen T, Sokka T. Distribution of radiation in synovectomy of the knee with 166Ho-FHMA using image fusion. Cancer Biother Radiopharm. 2005;20(3):333-7.

7. Jurgilewicz D. Scientific Meeting Report Radiosynovectomyradionuclide treatment of synovitis in the peripheral joints. Nucl Med Rev Cent East Eur. 2012;15(2):156-60.

8. Clinical Applications of SPECT/CT: New Hybrid Nuclear Medicine Imaging System. IAEA 2008 Aug. http://www-pub.iaea.org/ MTCD/Publications/PDF/TE_1597_Web.pdf. Accessed 20 May 2013.
9. Jahangier ZN, van der Zant FM, Jacobs JW, Riedstra HG, Gommans GM, Verzijlbergen JF, et al. The intra-articular distribution of 90yttrium does not influence the clinical outcome of radiation synovectomy of the knee. Ann Rheum Dis. 2007;66(8):1110-2.

10. Raja R, Chapman PT, O'Donnell JL, Ipenburg J, Frampton C, Hurst M, et al. Comparison of the 2010 American College of Rheumatology/European League Against Rheumatism and the 1987 American Rheumatism Association classification criteria for rheumatoid arthritis in an early arthritis cohort in New Zealand. J Rheumatol. 2012;39(11):2098-103. 